\title{
Study on the Problems of Punitive Compensation System of Food Safety Law
}

\author{
Yuxian Chen \\ Wuhan University of Science and Technology \\ Wuhan, China
}

\begin{abstract}
Food is essential in people's daily life and food problem is a matter of vital importance to the life of people, so we must lay stress on food safety. In recent years, food problems emerge one after another, resulting in bad influence nationwide and serious harmfulness against consumers' personal safety and health. Consumers have suffered the economic loss, yet they also have to face the mental distress and injury caused by food safety problems. The publication of punitive compensation of Food Safety Law has protected consumers' rights and interests in a better way to certain extent. There are still some problems, such as consumer scope and food safety standard, needing to be made clear.
\end{abstract}

Keywords-punitive compensation; nature; amount of compensation; consumer range

\section{INTRODUCTION}

In recent years, the food problems exposed are beyond count, such as, Sudan red duck eggs, Sanlu melamine milk powder, illegal cooking oil, lean meat powder, plasticizer, cadmium rice, tainted bean sprouts etc. Various safety problems are exposed in staple food, non-staple food, fish, meat and vegetables as well as every aspects relating to eating and drinking. Foods that are not conforming to safety standard will impair people's health immediately after they take the food, and some other will show their harmfulness after a long time. Tenfold of punitive compensation is added to the new Food Safety Law based on the previous amount in order to protect consumers' rights and interests better, which is a progress of legislation, but we should also be aware of its defects.

\section{Nature of Punitive Compensation}

The punitive compensation system of food safety is the specific application of punitive compensation in food consumption field. Punitive compensation of food safety refers to that if food producer or seller produces or sells the food not conforming to food safety standard illegally in the food production and transaction market, consumer can request the court to make judgment ordering the producer or seller to pay punitive damages thereby.

Food safety problem is becoming increasingly fierce though it is prohibited repeatedly, because it relates to the low cost. In order to make profit, food producers use every means including the addition of various food additives and non-food additives; they neglect legal rules and industrial standards to pursue lower cost and higher profit. Driven by the profit lever, most of the food producers produce various foods of poor quality which are harmful to human health and safety actively or non-voluntarily for profits and more market share. However, the supervision on food and punishment on food safety problems are not sufficient, and the problem food will make great profits, so the punishment from relevant departments seem to be not worthy of mention. Compensatory punishment was specified in Food Safety Law previously. Compensation is less than or equal to consumer's actual loss, and it is generally for property loss, yet the damage to physical and mental health due to food problems is hardly taken seriously. In comparison, punitive compensation in new Food Safety Law is already a significant progress in legislation. The nature of punitive compensation is analyzed below.

\section{A. "Additional" Punitive Compensation}

Different from compensatory compensation, punitive compensation offers more compensation to the sufferer than his actual property loss, thus the sufferer may get some mental comfort in addition to the material compensation, achieving the effect of compensation in true sense. Punitive compensation is the additional compensation based on compensatory compensation. The compensation amount is bound to be more than the amount of damage, which is of important significance for safeguarding consumer's rights and realizing social fairness and justice. The previous compensatory compensation is also called filling compensation. Under such system, it is hard for consumers, the sufferers of food safety problem, to get compensation equal to actual loss. In the food safety problem, as the sufferers, consumers suffer property loss, damage to physical health, and great mental pain. Moreover, the families, relatives and friends of the sufferer are also in a stage of anxiety. The previous compensatory compensation is the compensation equal to direct loss obtained by the consumers to certain extent, but their physical sufferings, family worries, the opportunities missed and other losses which cannot be calculated accurately are not compensated. In this sense, compensatory compensation is an insufficient compensation. Analyzing from this perspective, the additional compensation of punitive compensation is quiet sufficient for consumers and is beneficial to them. 


\section{B. "Disciplinal" Punitive Compensation}

The amount of punitive compensation should reach certain degree to make injuring party pay more to the sufferer on certain basis, so it is a punishment on the injuring party. Such punishment is of certain deterrent effect and the purpose of it can be realized. The punishment increases illegal cost to certain extent, which makes the injuring party have more misgivings when performing the illegal behaviors, so as to reduce the illegal behaviors and play a role of deterrence. It has achieved the deterrence purpose of law. It is also a warning to the people who want to behave illegally, enabling the reduction of similar behaviors, relieving more people from its harmfulness. The system reducing illegal behaviors by increasing illegal cost is an effective system.

\section{C. "Incentive" Punitive Compensation}

Its incentive nature is for consumers. Consumers only get the compensation roughly equal to property loss through compensatory punishment, without the legal cost and mental damage being compensated sufficiently. In addition to producing evidence, legal costs and traffic fees are still needed for the legal action. These costs are too high, yet the consumers may only get little compensation, but they have to spend a lot of time, energy and money. Considering these factors, most consumers are unwilling to take a legal action, and are forced to accept the bad luck. Restraining the anger and keeping silent blindly, however, will lead to more food safety problems which are more serious, making more people be harmed. As a result, compensatory compensation can improve consumers' enthusiasm in safeguarding their basic rights. Consumers can protect their own rights by law under the condition of getting more compensation. If more people choose to take a legal action to safeguard their rights and interest, the illegal behavior can be reduced and the problems can be solved completely.

\section{International Punitive Compensation}

This compensation system is in line with international ones. The indemnity compensation in food safety field has become a social development tendency, conforming to the trend of the times. The problems can also be handled in a fast and effective way even the legal action involves foreign affairs. At present, most countries of Anglo-American Legal System, such as British, Australia, America, Canada and New Zealand, have widely used the punitive compensation with obvious deterrent effect. When food safety problem occurs, many food enterprises take initiative to reach an accommodation with the consumers, so as to avoid the inconvenience and bad influence of legal action. In a word, it can protect consumers' rights and interests better, and encourage the food producers to produce the green and safety foods, which is beneficial to the whole food market.

\section{Problems of PUNITIVE COMPENSATION}

Although punitive compensation is a great progress compared with the compensatory compensation, we still need to be aware of the shortcomings of it. Different from compensatory compensation, punitive compensation offers the sufferers not only the actual loss they deserve to get, but also the additional compensation, to realize fairness in true sense, making the effect of compensation more obvious. With respect to enterprises violating the law, the increased burden means the increase of illegal cost, which can play a role of punishment and protect the rights and interests of consumers in a better way. In the following text, the shortcomings of punitive compensation will be discussed from the aspects of amount of compensation and consumer range.

\section{A. Unreasonable Aspects of Amount of Compensation}

The tenfold compensation standard of punitive compensation seems to be beneficial to consumers, but actually it is not. As a special commodity, the price of food is generally not high. For instance, as for the steamed bun and steamed stuffed bun costing 0.5 yuan or 1 yuan, if food safety problem occurs to such cheap food yet often in need, adverse influence will be caused to consumers. If they take a legal action, they have to spend a lot of time, energy and even the fees for traffic and test, yet the compensation they get according to law is five yuan, ten yuan etc., which obviously cannot make ends meet. In such circumstances, most consumers will give up the legal action after considering multiple factors, and bear the damage caused by food silently. The illegal behavior of the enterprise will not be punished without legal action against it, so its food will continue to circulate in the market, making more people hurt by it. This method is weak in punishment, having no influence on food producer, and similar food problems will not reduce but increase, which have encouraged the bad tendencies. Food producers are different in their size, and the variety and price of the food produced by them are also not the same. Some food producers are large-scale enterprises, even the tenfold compensation is of little importance to them. The profit gained illegally is extremely high, yet the cost and risk is low, so there are more and more foods not conforming to food safety standard on the market. What should also be considered is that different problem food results in different influence. Some foods only cause vomiting, diarrhea and other uncomfortable phenomenon, which has little influence on consumers' health and they can get recovery with a short rest. Some will cause food poisoning, which has great harm on the body. Not only expensive medical treatment fees are in need, but the consumers should also bear great physical and mental sufferings. In addition, the families are also worry about them. More serious food problems will cause grievous injury to people's health, and even unable to be cured, endangering their life. It can be seen that, food safety problems have verified degrees of injury. Moreover, the circulation range of food is different, so the scope of influence is also different. As a result, the unified tenfold compensation standard seems to be fair, but the fairness in form has covered the actual unfairness.

\section{B. Unreasonable Consumer Scope}

Speaking from the perspective of law, consumers should be the social members who purchase or use the commodities or accept the services for personal purpose. The consumers should be the ultimate user of products and services, but not the producer or operator. In other words, the purpose of 
consumers to buy commodities is for personal or household demand but not for operation or marketing, which is a most basic characteristic of consumers. The consuming activities of consumers include not only purchasing and using products for personal and household demand, but also accepting the services provided by others for such demand. However, no matter purchasing and using the commodities or accepting them, the purpose is just to satisfy personal and household demand instead of production and operation need. Viewing from this perspective, people who buy food for the purpose of consumption are consumers, and the professional extortioners for fraud fighting not belong to this scope. They take fraud fighting as their occupation, seeking the commodities with problems in product quality, packaging and label, term of validity, advertisement and propaganda, for a long term, and acquire certain profits by claiming or other means. Compared with the ordinary consumers, their motivation for consumption is to discover the problems existing in the commodities and get more compensation by legal action. With respect to the amount of procurement, they will buy more than the ordinary consumers, thus they can get more compensation due to great losses. As for the selection of commodities, in order to gain more compensation, professional extortioners for fraud fighting buy those foods which are more expensive than most of the foods. In addition, their internal personnel also have clear division of labor. More profits can be obtained with different division of labor and cooperation. Generally, they have more knowledge about commodities than the ordinary consumers, and better understanding of relevant laws and legal action methods. In Food Safety Law, they are not recognized as consumers due to those differences, because they are not the vulnerable group needing to protected, but the special group with impure motives to gain profits by making use of relevant provisions. Such limitation, however, is unfavorable for the ordinary consumers. The ordinary consumers have little understanding of foods, and they restrain their anger and keep silent considering high legal cost including time and energy, without safeguarding their rights and interests by law. The professional extortioners for fraud fighting can help ordinary consumers to know which food is harmful using their advantages and strong points, so that the consumers may keep away from those traps. Furthermore, the amount of compensation paid by food producers is also a kind of punishment on their illegal behaviors. The effect of deterrence by punishment is reflected in a better way, which can purify the market, reduce the similar illegal behaviors, and it is advantageous to the maintenance of economic order. Therefore, adjustment can be made in consumer scope.

\section{Suggestions For Problems of Punitive COMPENSATION}

\section{A. Reasonable Standard of the Amount of Compensation}

Do not use the unified tenfold compensation standard after food safety problem is occurred. The compensation may be made on the basis of consumers' actual loss. The compensation amount should not only reflect the nature of compensation, but the damage to consumers' health and mentality should also be made up, so that consumers may get more fairness as sufferers. It is hard for consumers to safeguard rights and interests as vulnerable group, so giving more compensation is conducive to the adjustment of their unfavorable position in the consumption relation. We should not give equal treatment to the damage to rights and interests of consumers caused by food safety problems of different degrees. The compensation can be made according to the extent of damage to rights and interests of consumers. The greater the damage, the more amount will be. Determining the amount of compensation in proportion will enable them to enjoy more fairness, and reasonable discrimination will optimize the result.

\section{B. Appropriate Expansion of Consumer Scope}

The existence of professional extortioners for fraud fighting will reduce the occurrence of food safety problems and maintain market order, so the inclusion of them in consumer scope can be considered. Although they have impure motives and gain profits by making use of the law compared with the ordinary consumers, they have more understanding of the market and the law, thus their legal action has already increased the illegal cost of food producers in a sense. The punishment of punitive compensation is reflected fully, which is also conducive to the maintenance of economic order and protection of other innocent consumers. We can recognize professional extortioners for fraud fighting as consumers in reasonable scope, and offer them less compensation than the ordinary consumers. With the increase of illegal cost, the illegal behaviors will be reduced, food market order be maintained, and transactions be encouraged.

\section{CONCLUSION}

Punitive compensation is additional, disciplinal, incentive and international-oriented, which conforms to international tendency and social development trend, being able to safeguard the legal rights and interests of consumers in a better way. Punitive compensation is already a huge progress when compared with compensatory compensation, but there are still shortcomings, such as unreasonable amount of compensation and narrow consumer scope. In view of these factors, we can make the standard of amount of compensation diversified, and include professional extortioners for fraud fighting into consumer scope, so that the punitive compensation may give full play to its advantages.

\section{REFERENCES}

[1] Tu Yongqian, Ma Haitian. Prospects for Food Safety Law Research: Research based on Relevant References of 2009-2016 [J]. Law Science Magazine, 2018, 39(06):105-114. (in Chinese)

[2] Ding Nan. On the Improvement of China's Food Safety Punitive Compensation System - and Evaluation on Article 148 of China's Food Safety Law [J]. Legal System and Society, 2018(09):20-21. (in Chinese)

[3] Li Runze. Usability of Punitive Compensation System in Food Safety Law [J]. Legality Vision, 2018(06):170. (in Chinese) 
[4] Guo Jianwei. Analysis of Punitive Compensation Usability in Food Safety Law [J]. Legal System and Society, 2015(29):61-62. (in Chinese)

[5] Wu Di. Research on Punitive Compensation System in Food Safety Field [J]. Legal \& Economy, 2017(12):95-97. (in Chinese)

[6] Han Jinda. Research on Shortcomings of Punitive Compensation System in Food Safety Law [J]. Legality Vision, 2017(13):227. (in Chinese)

[7] Yan Jiakun. Application of Punitive Compensation Responsibility in Food Safety Law [J]. Chinese Food Safety Magazine, 2016(33):45. (in Chinese)

[8] Zhang Xu. On the Punitive Compensation Mechanism of New Food Safety Law [J]. Legal System and Society, 2016(19):44-45. (in Chinese)

[9] Liu Junnan. Punitive Compensation System of Food Safety Law [J]. Legality Vision, 2016(10):162-163. (in Chinese) 